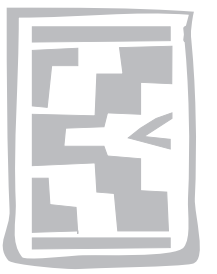

\title{
A sero-epidemiological survey of blood parasites in cattle in the north-eastern Free State, South Africa
}

\author{
M.S. MTSHALI ${ }^{1 *}$, D.T. DE WAAL ${ }^{2}$ and P.A. MBATI ${ }^{1}$
}

\begin{abstract}
MTSHALI, M.S., DE WAAL, D.T. \& MBATI, P.A. 2004. A sero-epidemiological survey of blood parasites in cattle in the north-eastern Free State, South Africa. Onderstepoort Journal of Veterinary Research, 70:67-75

A survey to determine the incidence of parasites in cattle $(n=386)$ was conducted in the north eastern Free State between August 1999 and July 2000. Giemsa-stained blood smears were negative for blood parasites. A total of $94 \%$ of the cattle were sero-positive for Babesia bigemina by indirect fluorescent antibody test while $87 \%$ were sero-positive for Anaplasma by enzyme-linked immunosorbent assay. The observation of negative blood smears but high incidence of positive serological results for Anaplasma and Babesia for the same group of cattle indicates that this area is endemic for these diseases but with a stable disease situation. All the animals were sero-negative for B. bovis and this is probably because the tick vector (Boophilus microplus) which transmits the disease is not present in the Free State Province. Two tick species belonging to the family Ixodidae were found on cattle, namely Boophilus decoloratus and Rhipicephalus evertsi evertsi. In the present study significant differences in seasonal burdens of $B$. decoloratus occurred, with the highest infestations recorded from February to June. The presence of $R$. evertsi evertsi throughout the year without any or with small fluctuations in winter months was observed, with a peak from February to May
\end{abstract}

Keywords: Anaplasma, Babesia, cattle, ELISA, epidemiology, IFAT

\section{INTRODUCTION}

Animal diseases in general and tick and tick borne diseases (TTBD) in particular are among the many factors which directly and indirectly hamper the growth of the livestock sector. Livestock is important because of the roles it play as a source of food, in generating employment, delivery of energy (dung,

* Author to whom correspondence is to be directed. E-mail: mtshalims@qwa.uovs.ac.za

1 Parasitology Research Programme, Qwa-Qwa Campus, University of the Free State, Private Bag X 13, Phuthaditjhaba, 9866 South Africa

2 Department of Veterinary Microbiology and Parasitology, Faculty of Veterinary Medicine, University College Dublin, Ireland

Accepted for publication 23 October 2004-Editor biogas), fertilizer, weed control, use of marginal lands, investment and savings, and transport (Sansoucy 1995). Tick-borne diseases of major economic importance in southern Africa which affect cattle are heartwater caused by Ehrlichia ruminantium, babesiosis caused by Babesia bigemina and Babesia bovis, anaplasmosis caused by Anaplasma marginale, and theileriosis caused by Theileria parva. Of much lesser importance in cattle are the generally non-pathogenic mild theilerioses caused by Theileria mutans, Theileria velifera and Theileria taurotragi, spirochaetosis (borreliosis) caused by Borrelia theileria, benign babesiosis caused by Babesia occultans, and bovine ehrlichiosis caused by Ehrlichia bovis (Horak 1982).

In Africa tick-borne diseases are important and they are considered as one of the greatest animal dis- 
ease problem. It is accepted that theileriosis caused by $T$. parva, dermatophilosis and heartwater are the major tick-borne or tick-associated diseases of grazing cattle. Babesiosis and anaplasmosis may be important in certain regions and may cause problems in grazing and zero-grazing situations. The complexity of determining the direct and indirect economic impact of tick-borne diseases and their control is reflected in the fact that only rough estimates are available for the cost of some of the components (De Castro 1997).

\section{MATERIALS AND METHODS}

\section{Study area}

The north-eastern Free State was divided into three study sites that included Harrismith (29 $5^{\prime} \mathrm{E}$, $\left.28^{\circ} 18^{\prime} S\right)$, Kestell (28 $38^{\prime} E, 2^{\circ} 20^{\prime} S$ ) and Qwa-Qwa $\left(28^{\circ} 50^{\prime} \mathrm{E}, 28^{\circ} 35^{\prime} \mathrm{S}\right)$ which are three established study sites of UNIQWA's Parasitology Research Programme. They are located at 42, 28 and $5 \mathrm{~km}$ respectively away from the Qwa-Qwa Campus of the University of the Free State.

\section{Experimental animals}

A total of 10-16 animals were randomly selected and examined monthly at each of the three study sites over a continuous period of 12 months from August 1999 to July 2000. They were kept under small-scale farming systems. During the day they graze on communal pastures. The usual grazing time is $7-9 \mathrm{~h}$ per day, the duration being determined by the time of the year. At night, cattle are herded, milked and kept in kraals with a manure floor.

\section{Parasitological diagnosis}

Cattle were individually restrained in a mobile facility consisting of a collecting kraal, race, crush and neck clamp. Thin and thick blood smears were made using standard techniques, fixed in absolute methanol and stained with a $10 \%$ neutral buffered Giemsa stain. Both thin and thick smears were examined using a $100 \mathrm{X}$ oil immersion objective lens of a Nikon SE light microscope.

\section{Serological diagnosis}

Blood samples were collected aseptically from the tail vein into $10 \mathrm{~m} \ell$ vacuum tubes (Becton Dickinson Vacutainer Systems Europe, UK) without anticoagulant. They were centrifuged for $30 \mathrm{~min}$ at 2000 $\mathrm{rpm}$ and the sera were harvested into cryovials, and kept at $-35^{\circ} \mathrm{C}$ until used for serological analysis. An indirect fluorescent antibody test described by Morzaria, Brocklesby \& Harradine (1977) was used to detect $B$. bigemina and $B$. bovis antibodies.

A competition inhibition enzyme-linked immunosorbent assay (CI-ELISA) described by Visser, McGuire, Palmer, Davis, Shkap, Pipanoe \& Knowles (1992) was employed to detect $A$. marginale antibodies, and the monoclonal antibody was obtained from the Onderstepoort Veterinary Institute, Pretoria, South Africa.

\section{Determination of packed cell volume values in the cattle}

Peripheral blood for packed cell volume was taken from the tip of the tail of the cattle by pricking the skin with the point of sharp scissors. The drop of blood that formed was collected into micro-haematocrit tubes. The blood was centrifuged in a microhaematocrit centrifuge (Gemmy Industrial Corp.) for $10 \mathrm{~min}$. A micro-haematocrit reader scale was used to determine the PCV readings of the studied animals.

\section{Collection and identification of tick species}

Ticks were collected on a monthly basis from August 1999 to July 2000 from the same groups of cattle from which blood samples had been collected. Only adult male and female ticks in all stages of engorgement were collected from the right-hand sides of the animals. The method of counting ticks on one body side only is generally used to estimate the overall level of tick infestation on animals (Hermans, Dwinger, Buening \& Herrero 1994; Dreyer, Fourie \& Kok 1998b). The right sides of animals were divided into 13 different regions and ticks from each region were collected separately (Dreyer et al. 1998b). These regions did not necessarily correspond to recognized anatomical regions. The position of attached adult ticks was first checked by visual examination and then palpating the hair coat of the animals. The ticks were removed using entomological forceps from each of the defined body areas and placed in labelled containers filled with $70 \%$ alcohol.

The ticks were identified to species level and counted under a standard stereoscopic microscope (Kyowa, Tokyo). Identification was done with the aid of the descriptions of Hoogstraal (1956) and Walker (1961). The number of ticks collected was multiplied by two to give an indication of total tick burden of each host. 


\section{Data presentation and analysis}

The data sets were analyzed statistically using analysis of variance techniques. The software programme used was the Statistical Analysis System (SAS) for all the serological data. Another software programme used was Statistica 1998 edition for Windows (StatSoft, Inc.). A one-way analysis of variance (ANOVA) test (Barnard, Gilbert \& McGregor 1993) was employed to determine significant differences in burdens of Boophilus decoloratus and Rhipicephalus evertsi evertsi during winter (May to July), spring (August-October), summer (November to January) and autumn (February to April). This was followed by the Least Significant Difference (LSD) test, to indicate the seasons causing the variance (Zar 1974). A one-way ANOVA-test followed by a LSD test was used to determine if any significant variability existed in seasonality of the tick species in the three different localities (Barnard et al. 1993).

\section{RESULTS}

\section{Parasitological screening for haemoparasites}

No blood parasite was detected in the thick and thin blood smears prepared from a total of 386 cattle examined in the three study sites. The majority of cattle in the area are of mixed-breed origin which are predominantly Friesian-crosses. All the animals sampled appeared healthy and did not show any clinical signs of disease.

\section{Serological diagnosis of Anaplasma and Babesia in the cattle}

The average seroprevalence of the cattle $(n=139)$ in the Harrismith area $\left(\chi^{2}\right.$ test, statistical value $=$
$79.317, \mathrm{df}=1$, prob $=0.001$ ) for $A$. marginale was $88 \%$ by ELISA while $92 \%$ of the animals were sero-positive $\left(\chi^{2}\right.$ test, statistical value $=98.482, \mathrm{df}$ $=1$, prob $=0.001$ ) for $B$. bigemina by IFAT. The sera from the Harrismith area were negative (100 $\%$ ) for $B$. bovis (Table 1).

The average seroprevalence of the cattle $(n=127)$ in the Kestell area $\left(\chi^{2}\right.$ test, statistical value $=59.598$, $\mathrm{df}=1$, prob $=0.001$ ) for $A$. marginale was $84 \%$ by ELISA while $91 \%$ of the animals were sero-positive (chi-square test, statistical value $=86.811$, df $=1$, prob $=0.001$ ) for $B$. bigemina by IFAT. The sera from the Kestell area were negative $(100 \%)$ for $B$. bovis (Table 2).

The average seroprevalence for the cattle $(n=120)$ in Qwa-Qwa ( $\chi^{2}$ test, statistical value $=73.633$, df $=$ 1 , prob $=0.001)$ for $A$. marginale was $89 \%$ by ELISA. All the animals were sero-positive (100\%) for $B$. bigemina by IFAT. The sera from the QwaQwa area were negative (100\%) for B. bovis (Table 3).

\section{Means of OD values of tested sera of the cattle as determined by ELISA}

The mean monthly value and standard deviation (SD) of optical density (OD) values of the tested sera from the cattle $(n=386)$ in the three areas were determined. The mean monthly OD values of the cattle in all the three sites ranged between 0.236-0.302 as shown in Table 4.

\section{Means of PCV values in the cattle}

The mean monthly PCV values of the cattle in all the three sites ranged between $26-31 \%$ as shown in Table 5.

TABLE 1 The prevalence of Anaplasma and Babesia in cattle $(n=139)$ in Harrismith as determined by ELISA and IFAT respectively

\begin{tabular}{|l|l|l|l|l|}
\hline Anaplasma marginale & Frequency & Percent & $\begin{array}{l}\text { Cumulative } \\
\text { frequency }\end{array}$ & $\begin{array}{l}\text { Cumulative } \\
\text { percent }\end{array}$ \\
\hline N & 17 & 12 & $\begin{array}{r}17 \\
139\end{array}$ & $\begin{array}{r}12 \\
100\end{array}$ \\
P & 122 & 88 & \multicolumn{1}{l|}{} \\
\hline Babesia bigemina & 11 & 8 & 11 & 8 \\
\hline N & 128 & 92 & 139 & 100 \\
P & \multicolumn{5}{|l}{} \\
\hline Babesia bovis & 139 & 100 & 139 & 100 \\
& 0 & 0 & 0 \\
\hline N & 0 & 0 & 0
\end{tabular}

$\mathrm{N}=$ the number of screened animals that were negative

$\mathrm{P}=$ the number of screened animals that were positive 
Blood parasites in cattle in north-eastern Free State, South Africa

TABLE 2 The prevalence of Anaplasma and Babesia in cattle $(n=127)$ in Kestell as determined by ELISA and IFAT respectively

\begin{tabular}{|l|l|l|l|l|}
\hline Anaplasma marginale & Frequency & Percent & $\begin{array}{l}\text { Cumulative } \\
\text { frequency }\end{array}$ & $\begin{array}{l}\text { Cumulative } \\
\text { percent }\end{array}$ \\
\hline N & 20 & 16 & 20 & 16 \\
P & 107 & 84 & 127 & 100 \\
\hline Babesia bigemina & 11 & 9 & 11 & 9 \\
\hline N & 116 & 91 & 127 & 100 \\
P & 127 & 100 & 127 & 100 \\
\hline Babesia bovis & 0 & 0 & 0 \\
\hline N & 0 & 0
\end{tabular}

$\mathrm{N}=$ the number of screened animals that were negative

$\mathrm{P}=$ the number of screened animals that were positive

TABLE 3 The prevalence of Anaplasma and Babesia in cattle $(n=120)$ in Qwa-Qwa as determined by ELISA and IFAT respectively

\begin{tabular}{|l|l|l|l|l|}
\hline Anaplasma marginale & Frequency & Percent & $\begin{array}{l}\text { Cumulative } \\
\text { frequency }\end{array}$ & $\begin{array}{l}\text { Cumulative } \\
\text { percent }\end{array}$ \\
\hline N & 13 & 11 & 13 & 11 \\
P & 107 & 89 & 120 & 100 \\
\hline Babesia bigemina & 0 & 0 & 0 & 0 \\
\hline N & 120 & 100 & 120 & 100 \\
P & \multicolumn{5}{|l|}{} \\
\hline Babesia bovis & 120 & 100 & 120 & 100 \\
& 0 & 0 & 0 \\
\hline N & 0 & 0 & 0 \\
P
\end{tabular}

$\mathrm{N}=$ the number of screened animals that were negative

$\mathrm{P}=$ the number of screened animals that were positive

TABLE 4 Mean monthly OD values of tested sera from cattle $(n$ $=386)$ in Harrismith, Kestell and Qwa-Qwa as determined by ELISA

\begin{tabular}{|l|l|l|l|}
\hline Month & $\mathrm{N}$ & Mean & SD \\
\hline August (1999) & 33 & 0.247 & 0.083 \\
September & 31 & 0.236 & 0.089 \\
October & 32 & 0.246 & 0.066 \\
November & 32 & 0.256 & 0.114 \\
December & 30 & 0.302 & 0.121 \\
January (2000) & 31 & 0.275 & 0.096 \\
February & 30 & 0.251 & 0.091 \\
March & 33 & 0.235 & 0.082 \\
April & 39 & 0.245 & 0.077 \\
May & 33 & 0.290 & 0.090 \\
June & 32 & 0.251 & 0.081 \\
July & 30 & 0.249 & 0.010 \\
\hline
\end{tabular}

$\mathrm{N}=$ the number of sampled animals

$\mathrm{SD}=$ standard deviation from the mean

TABLE 5 Mean monthly PCV values of cattle $(n=386)$ in Harrismith, Kestell and Qwa-Qwa

\begin{tabular}{|l|l|l|l|}
\hline Month & N & Mean & SD \\
\hline August (1999) & 33 & 29 & 6.33 \\
September & 31 & 29 & 6.29 \\
October & 32 & 28 & 4.94 \\
November & 32 & 31 & 4.58 \\
December & 30 & 28 & 6.86 \\
January (2000) & 31 & 29 & 6.78 \\
February & 30 & 30 & 3.88 \\
March & 33 & 30 & 5.05 \\
April & 39 & 28 & 4.92 \\
May & 33 & 29 & 5.53 \\
June & 32 & 26 & 6.11 \\
July & 30 & 26 & 6.90 \\
\hline
\end{tabular}

$\mathrm{N}=$ the number of sampled animals

$\mathrm{SD}=$ standard deviation from the mean 
TABLE 6 Tick species of the studied animals $(n=386)$ in Harrismith, Kestell and Qwa-Qwa

\begin{tabular}{|c|c|c|c|}
\hline Site & $\mathrm{N}$ & $\begin{array}{l}\text { Boophilus } \\
\text { decoloratus }\end{array}$ & $\begin{array}{l}\text { Rhipicephalus } \\
\text { evertsi evertsi }\end{array}$ \\
\hline Harrismith & 139 & 934 & 492 \\
\hline Kestell & 127 & 960 & 418 \\
\hline Qwa-Qwa & 120 & 1348 & 1778 \\
\hline Total & 386 & 3242 & 2688 \\
\hline
\end{tabular}

$\mathrm{N}=$ the number of sampled animals

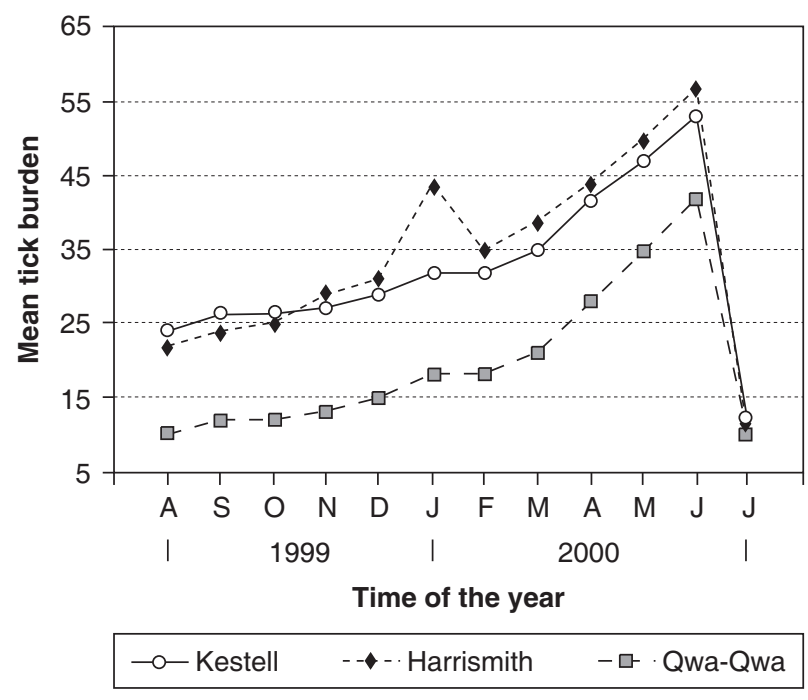

FIG.1 Mean monthly B. decoloratus burdens in cattle sampled in Harrismith, Kestell and Qwa-Qwa during a 12month study period (August 1999 to July 2000)

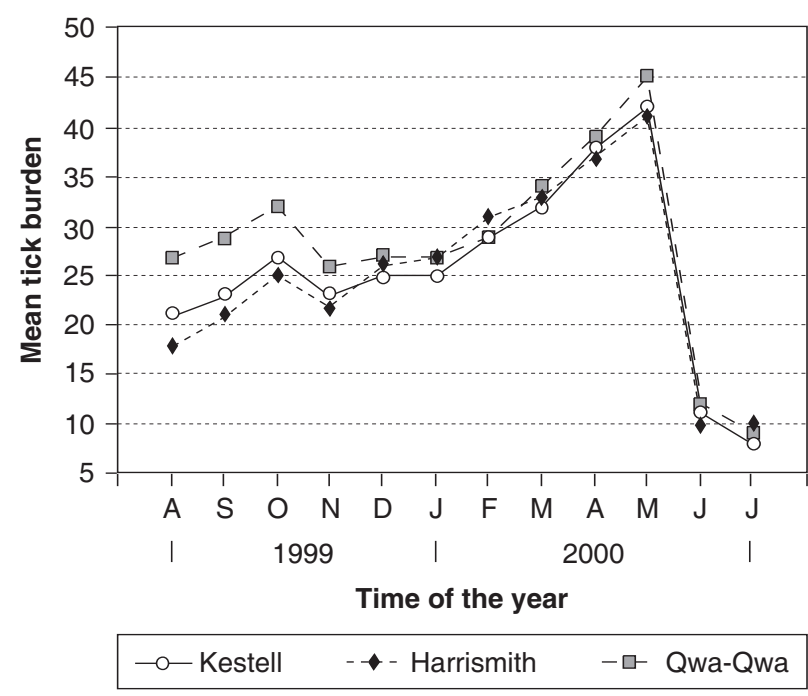

FIG. 2 Mean monthly R. evertsi evertsi burdens in cattle sampled in Harrismith, Kestell and Qwa-Qwa during a 12month study period (August 1999 to July 2000)

\section{Tick species infesting the cattle and their numbers}

A total of 5930 adult ticks belonging to two species were collected from the cattle $(n=386)$ during the period under review. These are summarized in Table 6. High tick infestations were observed on the animals from Qwa-Qwa. Boophilus decoloratus was generally the dominant species when comparing all the three study sites, whereas Rhipicephalus evertsi evertsi was only dominant in Qwa-Qwa.

Significant differences $(P=0.641$, at $5 \%$ significance level) in the seasonal burdens of $B$. decoloratus occurred, with the highest infestations recorded from February to June (Fig. 1). Peaks were observed in May to June and December to February.

Rhipicephalus evertsi evertsi was present throughout the year with some small fluctuations in the winter months, but with a peak in October (Fig. 2). Increased numbers of $R$. evertsi evertsi were present on the animals from February to May, with a peak occurring in May, dropping off to low levels in June and July in Kestell. A peak of $R$. evertsi evertsi was observed from February to May in both Harrismith, and Qwa-Qwa.

Seasonal burdens and variations of the two tick species were compared for the three localities, Harrismith, Kestell and Qwa-Qwa as is shown in Fig. 1 and 2. Seasonal variations among the three localities for the two tick species were small and mostly insignificant, and data from the three localities were thus combined for a discussion of the seasonal dynamics.

\section{DISCUSSION}

\section{Serological and parasitological diagnosis of parasites in the cattle}

It has been shown that, based on the information gained from a serological study, the immune status of cattle in an area can be classified into an endemically stable (81-100\% positive sera) situation, a situation approaching stability (61-80\%), an unstable $(21-60 \%)$ situation, a minimal disease situation (1-20\%), and a disease-free situation (0\% positive sera) (Norval, Lawrence \& Daillecourt 1983). Where the inoculation rate of Babesia and Anaplasma is adequate to ensure that all calves are infected while they are protected by innate and/or colostral immunity, clinical disease is minimal and endemic stability is achieved. The disruption of an existing situation of endemic stability is usually associated with drought 
conditions (De Vos 1979), or increased tick control (Norval et al. 1983). Endemic instability, on the other hand, describes the situation in a herd where some animals fail to become infected within nine months of birth. When such susceptible individuals encounter infected ticks, clinical disease develops (Dreyer, Fourie \& Kok 1998a)

With the IFAT a total of $94 \%$ of the studied animals were positive for $B$. bigemina indicating a significantly large number of animals exposed to this parasite. When comparing the three study sites, all the animals in Qwa-Qwa were positive (100\%) for $B$. bigemina, $92 \%$ of the animals in Harrismith were positive and $91 \%$ of the animals in Kestell were positive for $B$. bigemina by IFAT.

Based on the finding that $94 \%$ of cattle were seropositive for $B$. bigemina, it is evident that cattle in the north-eastern Free State fit into the group of infection rates that is indicative of an endemically stable situation. No clinical cases of babesiosis due to this organism were observed during the 12-month study period. Although there were differences in seroprevalence between the cattle in Harrismith, Kestell and Qwa-Qwa areas, these differences were small and not statistically significant. A similar study by Dreyer et al. (1998a) investigating tick-borne diseases of cattle in Botshabelo and Thaba Nchu indicated a situation approaching endemic stability with $62.42 \%$ of the studied animals having $B$. bigemina antibodies.

All the sera tested were negative for $B$. bovis in all the three study sites. As far as it is known, $B$. bovis is only transmitted by Boophilus microplus (De Vos 1979; De Vos \& Jorgensen 1992) which does not occur in the Free State Province (Howell, Walker \& Nevill 1978). Dreyer et al. (1998a) found an average seroprevalence of $19.47 \%$ against $B$. bovis in cattle sampled in the Botshabelo-Thaba Nchu area. These low seroprevalence indices indicated a situation of minimal disease, and the risk of clinical disease outbreak due to this organism was thus small. The occurrence of $B$. bovis antibodies in cattle of Botshabelo-Thaba Nchu area (Dreyer et al. 1998a), is difficult to explain, because no $B$. microplus ticks were found in this region (Dreyer 1997).

Endemic instability defines the situation in which some animals in the herd fail to become infected for a considerable period after birth. This could be due to a host-parasite imbalance resulting from infrequent transmission. Disease is then seen when susceptible animals in a herd encounter infected ticks. The creation of unstable situations in South Africa is to a large extent dependent on two factors: unfavourable climatic conditions and the injudicious control of ticks. One or both of these factors may influence the stability of either of the Babesia spp. in any given area (De Vos 1979).

The average seroprevalence of cattle for $A$. marginale was $87 \%$ in the three study sites. A seroprevalence above $81 \%$ is indicative of a situation of endemic stability. When comparing the three study sites, the animals of Qwa-Qwa had the highest positive percentage of $89 \%$. This was followed by Harrismith where $88 \%$ of the animals being positive for A. marginale by ELISA. In Kestell $84 \%$ of the animals were positive for $A$. marginale by ELISA.

Endemic areas of anaplasmosis in South Africa appear to have high vector activity and, for the maintenance of a stable situation, the obvious source of infection would be infected cattle. It is still believed that adequate vector challenge will ensure early exposure of calves and result in the development of protective immunity (Potgieter 1979).

Natural epidemic areas occur where none of the young calves are exposed to early infection because of the effect on vector survival resulting from geographical and climatic restrictions. Drastic fluctuations of these restrictions may result in the temporary settlement or elimination of vectors in these areas, with obvious consequences. Human-induced epidemics may result within endemic areas, if excessive tick control is practiced. If vector ticks are eradicated, a farmer will eventually breed susceptible stock. Under such conditions a lapse in the dipping programme, the possible introduction of carrier animals, the neglect by neighbours to dip their cattle, and the presence of certain wild ruminants and migrating cattle could lead to serious disease outbreaks (Potgieter 1979).

There was no significant difference $(P=0.006$, at $1 \%$ significance level) in the incidence of either anaplasmosis or babesiosis between the seasons. Further there was no significant $(P=0.008$, at $1 \%$ significance level) association on the occurrence of Anaplasma and Babesia infections when using the Likelihood Ratio of chi-square indicating that the two infections are independent.

The observation of negative blood smears but high prevalence of positive serological results for Anaplasma and Babesia for the same group of animals indicates that the north eastern Free State is endemic for these diseases but with a stable disease situation. It is known that indigenous breeds 
can become very resistant to ticks (Bonsma 1981) and acquire immunity to tick-borne diseases if exposed at an early age (Ross \& Lohr 1968).

\section{ELISA OD values of tested sera and $P C V$ readings of the cattle}

This study has shown that the animals had PCV ranges that fall within the normal PCV range of "healthy" cattle. This means that the animals studied are healthy carriers of anaplasmosis and babesiosis. Although anaemia can be caused by factors other than tick-borne diseases, it remains one of the most reliable indicators of tick transmitted diseases. The PCV profile and average PCV of cattle is affected by the number of ticks infecting animals and the prevalence of Anaplasma and Babesia. This observation can be used as an additional indicator for tick-borne diseases even when Anaplasma and Babesia cannot be detected by parasitological diagnostic tests.

The general linear models procedure showed no significant effect $(P=0.922$, at $5 \%$ significance level) of site, month, breed, $B$. bigemina or $A$. marginale on OD values. There was no significant effect $(P=0.0160$, at $5 \%$ significance level) of site, month, breed, $B$. bigemina or $A$. marginale on PCV when using the General Linear Models procedure, and there was no significant association $(P=0.7129$, at $5 \%$ significance level) between PCV and OD values when using correlation analysis (Pearson correlation coefficients).

\section{Tick species infecting the cattle}

A total of 5930 adult ticks belonging to two species were collected during 12-month period from August 1999 to July 2000 in the Harrismith, Kestell and Qwa-Qwa areas. Boophilus decoloratus the "blue tick" was generally a dominant species, but is inactive in winter and spring. In the present study significant differences in seasonal burdens of this onehost tick occurred, with the highest infestations recorded from February to June. This is similar to results obtained by Robertson (1981) in the Eastern Cape Province and Dreyer et al. (1998b) in the Free State Province, where $B$. decoloratus was abundant from May to June but sparse from July to January. In a study done by Rechav (1982) in the Eastern Cape, no definite pattern of seasonal occurrence was observed but the lowest numbers on hosts were also seen in early spring, with peaks in summer and autumn (February to June). The various peaks in adult infestation resulting in popu- lation "waves", indicate the completion of several generations in one year (Punyua, Latif, Nokoe \& Capstick 1991). Peaks were observed in the present study, namely, in May to June and December to January.

Boophilus decoloratus is responsible for the transmission of two tick-borne diseases, namely anaplasmosis and babesiosis. This tick is usually most evident from about September until the end of June, and may breed throughout the year in warmer areas. In colder climates, however, it is inactive in winter and early spring (Howell et al. 1978). The observation in our study is similar to that of Howell et al. (1978) in that a small rise in tick numbers was noted during September, and a peak in June when the blue ticks were mostly evident was obtained.

The positive correlation $\left(r^{2}=0.364, P<0.05\right)$ between burdens of tick species and warm or cold seasons was expected as ticks are ectotherms. Such a correlation was also reported by Fourie, Kok \& Heyne (1996) following their study in southwestern Free State. According to Rechav (1982), environmental temperature is probably the main regulating factor in the seasonal patterns of the blue tick.

The presence of $R$. evertsi evertsi the "red-legged tick" throughout the year with only small fluctuations in the winter months was also observed by Punyua et al. (1991), Fivaz \& De Waal (1993), and Dreyer et al. (1998b). In this study, the peak observed from March to May resembled the January to May peak on cattle in a KwaZulu-Natal study (Baker \& Ducasse 1967), the April to May peak in a study by Rechav (1982) in the Eastern Cape, the March to May peak in a study on sheep in the Free State (Horak, Williams \& Van Schalkwyk 1991), and the March to May peak on cattle in Botshabelo and Thaba Nchu (Dreyer et al. 1998b). Results obtained in this study indicated that temperature, and specifically the winter temperature, was probably the major factor regulating the seasonal activity of the red-legged tick. The continuous presence of adult ticks throughout the year indicates that more than one life cycle can be completed annually, as was suggested by Matson \& Norval (1977).

Rhipicephalus evertsi evertsi is one of the most important vectors of Theileria equi in horses in South Africa (Howell et al. 1978), and transmits B. bigemina (De Vos \& Jorgensen 1992) and A. marginale (Potgieter 1979) in bovines. Certain adult $R$. evertsi evertsi strains can produce a toxin resulting in "spring lamb paralysis" in lambs, kids and calves. 
High ear infestations with the immature stages of this species can result in ear irritation with secondary bacterial infections of ear canals (Howell et al. 1978).

Red-legged ticks are most active in summer, though some specimens can be found all through the year. In KwaZulu-Natal and the Eastern Cape the numbers of immature red-legged ticks start to increase early in November, are at their peak from January to April and then slowly decrease again. Adult numbers are highest from January to the end of May (Howell et al. 1978). The tick is inactive in winter and spring. Rhipicephalus evertsi evertsi was the second most abundant tick species in Harrismith and Kestell. This is probably due to the availability of its other preferred hosts, such as sheep and goats, which generally graze together with cattle.

Seasonal fluctuations of both tick species in the three localities were very similar but their burdens in cattle in Qwa-Qwa were significantly highest compared to the other two localities. A first possible reason for higher tick infestations in Qwa-Qwa was that the body condition of cattle in this locality was always poorer compared to that in the other two localities. This can result in a lowered tick resistance resulting in higher tick burdens (De Castro \& Newson 1993). A possible reason for the poor body conditions could have been the severe overgrazing of the veld in this specific locality. Farmers in this area appeared unmotivated and unwilling to herd their cattle to better grazing further away. A second possible reason for the higher tick burdens could have been the higher stocking densities, resulting in more contact with hosts (Hlatshwayo 2000). Another possible reason for higher tick burdens in Qwa-Qwa is that farmers in this area do not control ticks or tick-borne diseases. A possible reason these farmers not to control ticks is that most of them are resource-poor farmers, and they do not have the necessary resources and knowledge to control ticks (Hlatshwayo 2000).

\section{ACKNOWLEDEGMENTS}

We are grateful to the farmers in the north eastern Free State for their cooperation. We sincerely thank Dr Laura Lopez, Mr Olivier Matthee, Ms Andrea Spickett and Mr Jonas Komape of the Onderstepoort Veterinary Institute, Pretoria, South Africa for helping us with the sero-diagnostic techniques. We also thank Mr Mothea Tsosane, Mr Thobelani Lose and the late Ms Zolelwa Mxhebe for their assistance with data collecting. We would also like to acknowledge Dr Peter Njuho of the University of Natal, Pietermaritzburg for helping us with statistical analysis. This study was funded by the National Research Foundation and the University of the North, Qwa-Qwa Campus.

\section{REFERENCES}

BAKER, M.K. \& DUCASSE, F.B.W. 1967. Tick infestation of livestock in Natal. The predilection sites and seasonal variations of cattle ticks. Journal of South African Veterinary Medical Association, 38:447-453.

BARNARD, C.J., GILBERT, F.S. \& MCGREGOR, P.K. (Eds) 1993. Asking questions in biology. Harlow: Longman Scientific and Technical.

BONSMA, J.C. 1981. Breeding tick-repellent cattle, in Tick biology and control, edited by G.B. Whitehead \& J.D. Gibson. Proceedings of an International Conference held at the Tick Research Unit, Rhodes University, Grahamstown, South Africa, 7-29 January.

DE CASTRO, J.J. 1997. Sustainable tick and tickborne diseases control in livestock improvement in developing countries. Veterinary Parasitology, 71:77-97.

DE CASTRO, J.J. \& NEWSON, R.M. 1993. Host resistance in cattle tick control. Parasitology Today, 9:13-17.

DE VOS, A.J. 1979. Epidemiology and control of bovine babesiosis in South Africa. Journal of the South African Veterinary Association, 50:357-362.

DE VOS, A.J. \& JORGENSEN, W.K. 1992. Protection of cattle against babesiosis in tropical and subtropical countries with a live, frozen vaccine, in: Tick Vector Biology: Medical and Veterinary Aspects, edited by B. Fivaz, T. Petney \& I.G. Horak. Berlin: Springer-Verlag.

DREYER, K. 1997. Occurrence and control of parasites on cattle in urban and peri-urban environments with specific reference to ticks. M.Sc. thesis, University of the Free State.

DREYER, K., FOURIE, L.J. \& KOK, D.J. 1998a. Epidemiology of tick-borne diseases of cattle in Botshabelo and Thaba Nchu in the Free State Province. Onderstepoort Journal of Veterinary Research, 65:285-289.

DREYER, K., FOURIE, L.J. \& KOK, D.J. 1998b. Tick diversity, abundance and seasonal dynamics in a resource-poor urban environment in the Free State Province. Onderstepoort Journal of Veterinary Research, 65:305-316.

FIVAZ, B.H. \& DE WAAL, D.T. 1993. Towards strategic control of ticks in the Eastern Cape Province of South Africa. Tropical Animal Health and Production, 25:131-143.

FOURIE, L.J., KOK, D.J. \& HEYNE, H. 1996. Adult ixodid ticks on two cattle breeds in the south-western Free State. Onderstepoort Journal of Veterinary Research, 63:19-23.

HERMANS, P., DWINGER, R.H., BUENING, G.M. \& HERRERO, M.V. 1994. Seasonal incidence and hemoparasite infection rates of Ixodid ticks (Acari:Ixodidae) detached from cattle in Costa Rica. Review of Tropical Biology, 42:623-632.

HLATSHWAYO, M. 2000. Studies on ticks (Acari: Ixodidae) infesting cattle in the eastern Free State Province of South Africa: epidemiology, biology and control. M.Sc. thesis, University of the North.

HOOGSTRAL, H. 1956. African Ixodoidea. I. Ticks of the Sudan (with reference to Equatoria Province and with preliminary reviews of the genera Boophilus, Margaropus and Hyalom- 
ma. Research Report NM 005.050.29.07. Washington, D.C: Bureau of Medical Surgery, Department of the Navy.

HORAK, I.G. 1982. Parasites of domestic and wild animals in South Africa. XV. The seasonal prevalence of ectoparasites on impala and cattle in the northern Transvaal. Onderstepoort Journal of Veterinary Research, 49:85-93

HORAK, I.G., WILLIAMS, E.J. \& VAN SCHALKWYK, P.C. 1991. Parasites of domestic and wild animals in South Africa. XXV. Ixodid ticks on sheep in the north-eastern Orange Free State and in the eastern Cape Province. Onderstepoort Journal of Veterinary Research, 58:115-123.

HOWELL, C.J., WALKER, J.B. \& NEVILL, E.M. 1978. Ticks, mites and insects infesting domestic animals in South Africa. Part I. Descriptions and biology. Pretoria: Department of Agricultural Technical Services (Science Bulletin, No. 393)

MATSON, B.A. \& NORVAL, R.A.I. 1977. The seasonal occurrence of adult ixodid ticks on cattle on a Rhodesian farm. Rhodesian Veterinary Journal, 8:2-6.

MORZARIA, S.P., BROCKLESBY, D.W. \& HARRADINE, D.L. 1977. Evaluation of the indirect fluorescent antibody test for Babesia major and Theileria mutans in Britain. The Veterinary Record, 100:484-487

NORVAL, R.A.I., FIVAZ, B.H., LAWRENCE, J.A. \& DAILLECOURT, T. 1983. Epidemiology of tick-borne diseases of cattle in Zimbabwe. I. Babesiosis. Tropical Animal Health and Production, 15:87-94.

POTGIETER, F.T. 1979. Epizootiology and control of anaplasmosis in South Africa. Journal of the South African Veterinary Association, 50:367-432.

PUNYUA, D.K., LATIF, A.A., NOKOE, S. \& CAPSTICK, P.B. 1991. Tick (Acari: Ixodidae) infestations on zebu cattle in western Kenya: Seasonal dynamics of four species of ticks on traditionally managed cattle. Journal of Medical Entomology, 28:630-636.

RECHAV, Y. 1982. Dynamics of tick populations (Acari: Ixodidae) in the Eastern Cape Province of South Africa. Journal of Medical Entomology, 19:679-700.

ROBERTSON, W.D. 1981. A four year study of the seasonal fluctuations in the occurrence of the blue tick Boophilus decoloratus (Koch) in the coastal regions of the Eastern Cape, in Tick biology and control, edited by G.B. Whitehead, \& J.D. Gibson. Proceedings of an International Conference held at the Tick Research Unit, Rhodes University, Grahamstown. 27-29 January 1981.

ROSS, J.P.J. \& LOHR, K.F. 1968. Serological diagnosis of Babesia bigemina infection in cattle by the indirect fluorescent antibody test. Research in Veterinary Science, Kabete Kenya, 9:557-562.

SANSOUCY, R. 1995. Livestock-a driving force for food security and sustainable development. World Animal Review, 84/85:5-17.

VISSER, E.S., MCGUIRE, T.C., PALMER, G.H., DAVIS, W.C., SHKAP, V., PIPANOE. \& KNOWLES, D.P. 1992. The Anaplasma marginale msp5 gene encodes a 19-kilodalton protein conserved in all recognized Anaplasma species. Infection and Immunity, 60:5139-5144.

WALKER, J.B. 1961. Some observations on the classification and biology of ticks belonging to the genus Rhipicephalus with special reference to the immature stage. East African Medical Journal, 38:232-246.

ZAR, J.H. 1974. Biostatistical analysis. Englewood Cliffs, New Jersey: Prentice-Hall Inc. 